Tesis. Año 13, 12(15), 2019, 141-150

\title{
Narrativas alternativas de la violencia en Rosa Cuchillo y La sangre de la aurora
}

\author{
Carmen Jhoana Díaz Atilano \\ diazatilano.carmenjhoana@gmail.com
}

\section{Resumen}

El presente estudio se propone analizar las formas narrativas alternativas con que dos novelas, Rosa Cuchillo (1997) y La sangre de la aurora (2013), recrean el Conflicto Armado del Perú. Sostendremos que ambas, como parte de una poética personal de sus autores, emplean recursos como la fragmentación, la elipsis y la polifonía para dar cuenta del contexto de violencia. Además, en ambos textos, se destaca el elemento femenino como narrador y como personaje empoderado.

Palabras clave: formas narrativas, Conflicto Armado del Perú, polifonía, personaje femenino.

\section{Abstract}

The present study intends to analyze the alternative narrative forms with which two novels, Rosa Cuchillo (1997) and Blood of the dawn (2013), recreate the Armed Conflict of Peru. We will argue that both, as part of a personal poetics of their authors, use resources such as fragmentation, ellipsis and polyphony to account for the context of violence. In addition, in both texts, the feminine element stands out as a narrator and as an empowered character.

Key words: narrative forms, Armed Conflict of Peru, polyphony, female character. 


\section{Narrativas alternativas de la violencia en Hosa Cuchillo y La sangre de la aurora}

\section{Introducción}

Tanto Óscar Colchado Lucio como Claudia Salazar son dos autores reconocidos en la esfera literaria peruana. El escritor ancashino y la escritora limeña, radicada en New York, han ganado múltiples reconocimientos por su obra narrativa. Así, por ejemplo, Rosa Cuchillo (1997) ganó el Premio Nacional de Novela de la Universidad Federico Villareal y La sangre de la aurora (2013) obtuvo el Premio Las Américas 2014. Ambos coinciden en recrear, en sus respectivas novelas, el contexto de violencia que se vivió durante el Conflicto Armado Interno (CAI) en nuestro país.

Además de la confluencia temática de estos textos, queremos sostener, como hipótesis, que ambos se ofrecen como narrativas alternativas frente al corpus que cuenta los hechos de manera unívoca, omnisciente y que legitima discursos de poder dominantes. Las novelas que estudiamos se configuran como divergentes pues representan la violencia a través de estrategias narrativas que evidencian la complejidad de perspectivas. Además, tienen el valor de destacar la figura femenina, no solo como portadora de voz y memoria, sino también por la agencia de sus personajes.

El proyecto de investigación propuesto se ayudará de la Literatura Comparada, como herramienta crítica para establecer las semejanzas y diferencias entre ambas novelas. Así mismo, nos serviremos de la narratología para analizar las formas narrativas utilizadas y de la teoría de género para entender la agencia de los personajes femeninos en los textos.

\section{Formas de enunciación alternativa}

Sostenemos que ambas novelas comparten formas de enunciación alternativas, tanto en su forma como en su contenido. En su forma, porque las dos comparten rasgos como la polifonía y el discurso fragmentado que se distinguen de las 
narraciones tradicionales monológicas y unívocas de la historia. Estas últimas han constituido la versión dominante del canon de nuestra literatura (baste citar a Lituma en los andes de Mario Vargas Llosa, Abril Rojo de Roncagliolo y La hora azul de Alonso Cueto), no solo por la consagración de sus autores sino también porque constituyen la forma mayoritaria de este tipo de novelas. Entre los textos del CAI, los que estudiamos se configuran como una alternativa discursiva que conlleva implicancias éticas: a partir del uso de múltiples voces narrativas (incluyendo la de los indígenas y mujeres) se incorporan las memorias comúnmente invisibilizadas y con ello el lector puede acceder a diversas perspectivas de los hechos. En el contenido, ocurre algo similar. Se plantea una diferenciación respecto a otras novelas ya que ofrecen protagonismo a personajes femeninos. No solo a través de su propia narración, sino también con la configuración de mujeres cuya performance cuestiona o desestabiliza, de algún modo, el sistema patriarcal. Tiene relevancia que estos personajes actúen de manera empoderada en las novelas del CAI, pues demuestran que un fenómeno excesivo de violencia puede permitir un cuestionamiento de los valores dominantes.

Uno de los primeros textos que destaca esta divergencia fue el de Víctor Quiroz. En su ponencia, titulada "La violencia narrativa como estrategia discursiva crítica contra el autoritarismo y el falocentrismo en la novela La sangre de la aurora de Claudia Salazar" (2014) ubica la novela dentro del corpus de la narrativa peruana actual. Además, con ayuda de la categoría "violencia narrativa" desarrolla su postura del cuestionamiento al falocentrismo hegemónico. De esta forma, desarrolla la idea de formas de enunciación distintas, tanto a nivel formal (recursos narrativos) como a nivel de contenido, en la medida que aquellas cuestionan modos de pensamiento dominantes.

Como mencionamos, Quiroz ubica a Rosa Cucbillo (pero también a La sangre de la aurora) en el corpus de la novelística peruana del CAI. El investigador distingue dos tipologías narrativas para representar la violencia. Esta se puede manifestar a través de las formas de ficcionalización de la memoria colectiva sobre el CAI y en relación a los mecanismos de cómo se construye la otredad. De ahí que la primera tipología esté emparentada con una narrativa monológica que ofrece una única versión de los hechos, con los discursos de poder hegemónicos que intentan mantener las jerarquías socioculturales o muestra predilección por los códigos del relato policial. En este rubro, cita a novelas como $\mathrm{La}$ hora azul de Alonso Cueto, Abril Rojo de Santiago Roncagliolo y Lituma en los andes de Mario Vargas Llosa. Por el contrario, la otra tipología se caracteriza por construir un lugar de enunciación contrahegemónico, por presentar un discurso descolonizador de las diferencias sociosexuales y el uso de la polifonía. Dentro de este rubro, Quiroz ubica novelas como Adiós Ayacucho de Julio Ortega y Rosa Cuchillo de Óscar Colchado Lucio. A partir de los rasgos textuales de La sangre de la aurora, el investigador la ubica también en el segundo grupo. 
Nosotros concordamos con esta perspectiva puesto que el uso de la polifonía en ambas novelas actualiza múltiples memorias, permitiendo así obtener al lector una visión más completa de los acontecimientos. Además, al ser voces femeninas las que narran el conflicto se visualiza a sujetos tradicionalmente silenciados y se cuestiona un sistema patriarcal imperante. De este modo, como menciona Quiroz:

Lo que interesa resaltar de esta propuesta estético-ideológica es que presenta una singularidad con relación a las otras novelas antes mencionadas: es evidente que dicha actitud contrahegemónica es primordialmente enunciada desde una perspectiva de género, aspecto que se desarrolla de modo multifacético y sistemáticamente a lo largo de la narración. (Quiroz, 2014, p. 9)

Pese a que concordamos con Quiroz en el carácter disidente de estas narrativas, nos distanciamos de su perspectiva de considerarlas como contrahegemónicas, por su connotación política. Nosotros creemos que, en la actualidad, este tipo de narrativas resultan de una apuesta poética de los autores y, por ello, la denominamos alternativas. Resultan ser una opción entre otras, pero su importancia radica en la posibilidad de ofrecer al lector una multiplicidad de puntos de vista sobre los hechos, y sobre todo, el de las mujeres, tradicionalmente silenciada. Esta precisión permite observar que la complejidad narrativa de las novelas objeto de análisis no se relaciona necesariamente con una opción política (homologar unas formas narrativas con un contenido determinado es ignorar la historia de las formas literarias en los últimos 150 años), sino que la diversidad de perspectivas se puede comprender como una opción por asumir la complejidad del referente narrado.

\section{Antecedentes de nuestro estudio}

En relación a los estudios comparativos entre las novelas que estudiamos y otros textos que representan el tema del CAI podemos mencionar el artículo de Manuel Prendas Guardiola (2010) porque evidencia las constantes temáticas en tres novelas peruanas sobre el CAI: La hora azul de Alonso Cueto, Abril Rojo de Santiago Roncagliolo y Rosa Cuchillo de Óscar Colchado Lucio. El investigador menciona que, aunque esta última no sigue las pautas de la ficción policial, comparte con las otras dos la búsqueda de la verdad. Según él, en Rosa Cuchillo esto se hace evidente porque la protagonista vaga por el mundo de ultratumba de la cosmogonía andina en busca de su hijo. Nosotros no concordamos con esta postura puesto que Rosa busca a Liborio en el más allá, pero no para encontrar la verdad, pues ella ya sabe que su hijo ha muerto. Al inicio de su viaje por ultratumba, se entera que su hijo está ya en el Hanaq Pacha, se alegra y pretende llegar hasta ahí, pero no persigue ninguna verdad. 
Por otro lado, establece las constantes temáticas que comparten las tres novelas en función de cuatro criterios: el espacio, la mujer víctima, jerarquías sociales y religión. Nos interesan los dos primeros puntos pues los abordamos con más detalle en el estudio. En relación al primero, concordamos con la ubicación espacial andina de Rosa Cuchillo. Respecto a la mujer víctima, matiza su postura al afirmar que Rosa se configura como un personaje doliente pero emancipado de los hombres. Además, señala que la maternidad es un tópico común que comparte con Miriam de La hora azul. Consideramos que otras novelas del CAI, como Ese camino existe, también destacan la figura de la madre, pero no necesariamente desde su propia narración como en el caso de Rosa Cuchillo y de La sangre de la aurora en los personajes de Marcela y Modesta.

Otro estudio digno de mención es el artículo de Juan Carlos Galdo titulado "Algunos aspectos de la narrativa regional contemporánea: los casos de Enrique Rosas y Colchado Lucio” (2000). En él, el crítico destaca la relevancia del discurso histórico-mítico y la incidencia de la tradición oral como núcleo de la construcción de los textos. Lo interesante de su postura es que haciendo uso de la terminología bajtiniana, denomina como "híbridas" a estas narrativas. Entiende lo híbrido como una complejidad estructural donde la pluralidad de voces y perspectivas desestabilizan la lengua unitaria y autoritaria y concurren más allá de lo estrictamente poético-discursivo. Concordamos en que Rosa $\mathrm{Cu}$ chillo encaja en dicha designación, ya que actualiza una diversidad de voces narrativas y evidencia la precariedad de un discurso homogéneo asociado a la modernidad. Incluso podemos afirmar que La sangre de la aurora también es una narrativa híbrida, pero lo que diferencia a las novelas que estudiamos de, por ejemplo, la obra de Enrique Rosas es que ellas no solo presentan múltiples perspectivas sino que una de ellas es femenina.

En relación a la perspectiva femenina, cabe mencionar el artículo de Claudia Salazar, crítica de Rosa Cuchillo y autora de La sangre de la aurora, titulado: "Género y violencia política en la literatura peruana: Rosa Cuchillo y Las hijas del terror" (2013). En este, destaca el empoderamiento y la agencia de los personajes de Rosa y Angicha en la novela de Colchado Lucio. Señala que en ambos textos la mujer violada aparece como el cuerpo significante más potente del conflicto pues es metáfora de la nación desgarrada. Concordamos con su lectura - desde la teoría de género- de los personajes femeninos, pues son fuertes, pero presentan matices en su configuración. Además, esta perspectiva no solo se hace evidente en su crítica a Rosa Cuchillo, sino también en la configuración de los personajes de su propia novela: La sangre de la aurora. Un enfoque como el suyo refuerza nuestro parecer de que el elemento femenino, ya sea desde su narración o como personaje, es clave para comprender a los textos que estudiamos. 


\section{Resultados en torno al lugar de enunciación y el personaje femenino}

Los objetivos de este estudio son los siguientes: analizar los recursos narrativos empleados como una forma ficcional alternativa de contar la historia del CAI; explicar la agencia del personaje femenino en su modo particular de entender el conflicto y relatarlo; y evidenciar la posibilidad liminal del lenguaje narrativo para relatar el tema de la violencia.

Con ayuda de términos tomados de la narratología en relación al espacio, tiempo y discurso en ambas novelas, se aprecia cómo las formas narrativas fragmentarias en ambas novelas denotan una apuesta poética frente a las formas hegemónicas de contar el acontecimiento de violencia que vivió nuestro país.

En el caso de La sangre de la aurora, observamos que utiliza recursos narrativos vanguardistas. Lo primero que llama la atención del lector es el carácter fragmentario de la obra. Comienza con una cita de Marx sobre la importancia de la cuota femenina en los cambios sociales, continúa con una narración libre sobre los apagones que provocaba Sendero Luminoso, para recién dar paso a la voz de la primera narradora: Marcela o camarada Martha. Por lo tanto, lo primero que salta a la vista es que se trata de un texto collage, en el que se intercalan no solo distintas voces narrativas sino también distintos tipos de discurso. Esta forma narrativa escogida no es gratuita: la fragmentación implica que la violencia ha sobrepasado el mundo representado y se ha convertido también en un modo de narrar el conflicto. En otras palabras, la violencia no solo es un tema de la novela, sino que también se expresa en el plano formal, pues se apuesta por narrar tales hechos desde un lenguaje afectado también por aquella.

Los recursos vanguardistas de esta obra aparecen a lo largo de su extensión, pero hay algunos que son capitales de mencionar. Por ejemplo, en la narración sobre los apagones con que empieza la novela, observamos que esta no está escrita con letra inicial mayúscula, que las pausas no se marcan con comas ni puntos seguidos, es decir, que hay ausencia de signos de puntuación. Se trata, además, de una narración que aglutina frases, sin un orden aparente, que se asemeja a un fluir de la conciencia pero donde también el flujo verbal de este ha sido violentado. Podemos apreciar lo dicho en una cita de la misma novela:

Apagón total oscuridad ¿¿dónde fue? en todas partes ¿de dónde vino? torres tensas altas cayeron arrodilladas bombas explotar todo arrasar volar reventar ¿estabas con el grupo? cocinando en mi casita esperando mi esposo apagón pasando a máquina las actas de la reunión apagón revelando unas fotos apagón. (Salazar, 2013, p. 11)

En la cita, cabe resaltar que el aglutinamiento de frases se corresponde con el de distintas voces narrativas. Primero, observamos que dos de ellas establecen un diálogo, una pregunta y la otra contesta en relación al tema de los apagones. Además, a la pregunta “¿dónde fue?", la respuesta evidencia la configuración de 
un espacio universal (“en todas partes"), tal como se demostrará más adelante. A la siguiente interrogante "¿de dónde vino?", se contesta que "torres tensas altas cayeron arrodilladas", con lo cual se precisa la causa de la falta de luz. Pero, además, se establece metafóricamente una imagen que connota subordinación: las torres se arrodillan ante la violencia de quienes las hacen caer. Esta sumisión se justifica por el contexto de violencia que se completa después: "bombas explotar todo arrasar volar reventar".

En el caso de Rosa Cuchillo, una de las formas narrativas que destaca es el cambio de narradores. La novela empieza con la narración en primera persona de Rosa y luego se alterna con la de Liborio. Al igual que en La sangre de la aurora nos encontramos ante una novela polifónica (los acontecimientos se narran desde distintas voces narrativas que encarnan, a su vez, distintos puntos de vista) ya que la perspectiva de cada personaje, portavoz de los hechos, es individual pero, al mismo tiempo, establece relaciones con las demás. Creemos que dentro de dicha polifonía, destaca la versión de Rosa Cuchillo, pues ella es la protagonista de la novela.

Aquí, la protagonista (Rosa Cuchillo) relata los hechos como narrador autodiegético, pero también está presente un narrador heterodiegético que focaliza desde su perspectiva (Pérez Orosco, 2011, p. 48). Veamos algunos ejemplos textuales:

Suspiré hondo antes de alejarme, recordando mi mocedad, cuando alegre correteaba entre los maizales jugando con mi perro Wayra, haciéndolos espantar a los sirguillitos, esas menudas avecitas amarillas que entre una alborozada chillería venían a banquetearse con los choclos. (Colchado, 2005, p. 8)

Cuando por fin asomó a la placita silenciosa de Illaurocancha, sufrió un ataque de nervios, y empezó a gritar y a llamar a su hijo, a destrozarse la ropa arañando sus carnes. Recién ahí asomaron algunos viejos y mujeres a auxiliarla, a darle agüita, masajes, en tanto ella se convulsionaba y apretaba los dientes botando espumarajos, quedándose después rígida, con el cuerpo que se le enfriaba. (Colchado, 2005, p. 206)

Como vemos, en la primera cita aparece un narrador autodiegético, pues es la propia Rosa quien desde su perspectiva nos cuenta su historia. Asistimos, como lectores, a sus años de juventud, cuando junto a su perro Wayra, se dedicaba a jugar y a las labores propias del campo. En la segunda cita, en cambio, un narrador heterodiegético - pero desde la focalización de Rosa- describe las consecuencias que experimenta la protagonista tras encontrar los restos de su hijo muerto.

Esta doble narración que involucra al personaje de Rosa (autodiegética y heterodiegética) refuerza la idea de que ella es la protagonista, ya que observa el 
mundo y nos lo muestra desde más puntos de vista que cualquier otro personaje. La narración de Liborio, hijo de Rosa y segundo personaje en importancia de la historia, contextualiza el ambiente de violencia del mundo representado, ya que él cuenta cómo el accionar de Sendero Luminoso impacta en el mundo andino. Además, su muerte en actividad guerrillera justifica narrativamente la de su madre al inicio de la novela.

Como vemos por el análisis de los fragmentos de los textos que hemos citado, estas narrativas se alejan de una voz heterodiegética y omnisciente para dar paso a la polifonía y con ello no solo cambian un simple aspecto formal, sino que instauran una nueva perspectiva de los acontecimientos. A través del análisis, se descubre que tanto Rosa Cuchillo como La sangre de la aurora comparten formas de enunciación alternativas respecto a otro grupo de novelas del CAI cuyas formas narrativas legitiman discursos dominantes (Quiroz, 2014, p.7-11). Este tipo de enunciación, en ambas, resulta tanto de las características textuales que presentan (p.e. la fragmentación narrativa, la polifonía, la elipsis) como del modelo de lectura que proponen los textos: la reconstrucción crítica. Las novelas que estudiamos son narradas desde múltiples perspectivas, incluyendo las femeninas, mientras que las otras solo dan una versión única de la historia. El uso de este recurso ofrece un punto de visto más diverso y plural del conflicto y coacta al lector a recepcionarlo con una participación activa.

Asimismo, gracias a términos tomados de la teoría de género (como la agencia, el empoderamiento o la sororidad) vemos la importancia del elemento femenino en ambas novelas. La mujer, como personaje, aparece como un símbolo de resistencia frente a las imposiciones patriarcales de violencia: es madre, esposa y portadora de la memoria. Su protagonismo y el motivo de que lo tenga dentro de estos relatos, implica que la violencia política ha desestabilizado, en cierta medida, el sistema patriarcal moderno que subalterniza a la mujer. Si bien en su construcción, estos cumplen algunos roles propios de una sociedad patriarcal (ser madre, esposa y objeto sexual), presentan matices que evidencian resistencia a estas imposiciones. En ambos casos, la importancia de que sea un personaje femenino quien narre la historia (Rosa en Rosa Cuchillo, y Marcela, Modesta, Melanie en La sangre de la aurora) nos permite obtener otra perspectiva de ella, tradicionalmente silenciada. La agencia de estos personajes logra cuestionar un sistema falocéntrico dentro de la ficción, con lo cual se reconfigura lo femenino en novelas cuyo referente es el Conflicto Armado Interno.

Por lo tanto, contamos con personajes que superan con creces la imagen estereotipada de la mujer sumisa. A partir del ejercicio de su maternidad y su sexualidad, aquellos rompen con los cánones tradicionales. Estas narrativas, a través del discurso y representación de sus personajes principales, se rebelan contra una manera unívoca de entender los hechos acaecidos, propone nuevas 
perspectivas y maneras de pensar la imagen de la mujer, y con ello se aleja de los lugares comunes de nuestro tradicional imaginario cultural.

\section{Conclusiones}

Creemos que Rosa Cuchillo y La sangre de la aurora encierran un compromiso ético al representar de manera discursiva la heterogeneidad social. De esta forma, se convierten narrativas divergentes al integrar y revalorizar formas subalternas de enunciación. La violencia en ambas novelas no solo se representa como un tópico, sino a través de formas narrativas. Gracias al empleo de estrategias como el uso de la polifonía, la fragmentación y el silencio evidencian que el lenguaje con que se cuentan estos hechos también ha sido violentado. Además, la figura femenina adquiere relevancia, como portavoz de lo acaecido y como personaje empoderado. De este modo, dentro de la ficción, se da cabida a otras perspectivas, hegemónicamente silenciadas. Por último, respecto a los límites de la enunciación, concluimos que los vacíos textuales son tan importantes como lo que se relata, y estos, muchas veces, obligan al receptor a tener una participación activa y completar el sentido a través de una lectura crítica.

\section{Referencias bibliográficas}

\section{Bibliografía primaria}

Salazar Jiménez, C. (2013). La sangre de la aurora. Lima, Perú: Estación La Cultura S.A.C.

Colchado Lucio, Ó. (2005). Rosa Cuchillo. Lima, Perú: Editorial San Marcos.

\section{Bibliografía secundaria}

Cárdenas Moreno, M. (2016). Ruptura del cuerpo y ruptura del lenguaje en la novela de la memoria histórica en el Perú. Estudio comparativo de Adiós Ayacucho de Julio Ortega y La sangre de la aurora de Claudia Salazar. Revista del Instituto Riva-Agüero, vol.1, №2, pp. 11-46.

Galdo, J.C. (2000). Algunos aspectos de la narrativa regional contemporánea: los casos de Enrique Rosas Paravicino y Óscar Colchado Lucio. Lexis XXIV, No 1 , pp. 93-108.

Osorio Mendoza, N. (2009). La comunicación enunciativa en la novela Rosa Cuchillo de Óscar Colchado Lucio. Arequipa, Perú: UNSA.

Perez Orozco, E. (2011). Racionalidades en conflicto. Cosmovisión andina (y violencia política) en Rosa Cuchillo de Óscar Colchado. Lima, Perú: Pakarina Ediciones.

Prendes Guardiola, M. (2010). Constantes temáticas en tres novelas peruanas sobre la época del terrorismo. Romance Notes, vol.50, N², pp. 229-239. 
Quiroz Ciriaco, V. (2006). Pensamiento andino y crítica postcolonial. Un estudio de Rosa Cuchillo de Óscar Colchado. Tesis para optar el título profesional de Licenciado en Literatura. Lima, Perú: Universidad Nacional Mayor de San Marcos.

- (2014). La violencia narrativa como estrategia discursiva crítica contra el autoritarismo y el falocentrismo en la novela La sangre de la aurora de Claudia Salazar". Ponencia presentada en el Congreso Perú Transatlántico. Intercambios, reapropiaciones, inclusiones: balance de la modernidad. Lima, Perú: Brown University y Pontificia Universidad Católica del Perú.

Salazar, C. (2013). Género y violencia política en la literatura peruana: Rosa Cuchillo y Las hijas del terror. Confluencia, vol. 29, $\mathrm{N}^{\circ} 1$, pp. 69-80.

\section{Bibliografía complementaria}

Bal, M. (1990). Teoría de la narrativa (Una introducción a la narratología). Madrid, España: Ediciones Cátedra, S.A.

Butler,J. (2002). Cuerpos que importan. Sobre los limites materiales y discursivos del "sexo". Buenos Aires, Argentina: Paidós.

Comisión De La Verdad y Reconciliación. (2003). Informe final. Recuperado de http://www.cverdad.org.pe/ifinal/. Consultado el 13 de noviembre del 2018 a las 17 horas.

García Peinado, M.A. (1998). Hacia una teoría general de la novela. Madrid, España: Arco/Libros, S.L.

Genette, G. (1989). Figuras III. Barcelona, España: Editorial Lumen, S.A.

Guillén, C. (1985). Entre lo uno y lo diverso. Introducción a la literatura comparada. Barcelona, España: Critica.

Lamas, M. (Comp.). (1996). El género: la construcción cultural de la diferencia sexual. México D.F., México: Coordinación de Humanidades, Programa Universitario de Estudios de Género, UNAM/ Grupo Editorial Miguel Ángel Porrúa.

Martín Jiménez, A. (1998). Literatura general y “Literatura comparada”: la comparación como método de la Crítica Literaria. Repositorio Documental de la Universidad de Valladolid. Castilla, España: Universidad de Valladolid, pp. 129-150.

Moi, T. (1988). Teoría literaria feminista. Madrid, España: Cátedra.

Terán Morvelli, J. (2017). La narrativa de la violencia en el Perú. Una primera tipología. Entre caníbales, N 5 . Recuperado de http://entrecanibales.net/mayo2017/articulo-jorge-teran.html. Consultado el 15 de noviembre del 2018 a las 14 horas. 